\title{
24. Repetition using PERFORM..TIMES
}

The computer can be instructed to repeat a certain paragraph a number of times using PERFORM .. TIMES.

e.g. PERFORM GET-STAFF-DETAILS 5 TIMES.

It is also possible to make the computer process a group of consecutive paragraphs a given number of times.

e.g. PERFORM GET-DETAILS THRU PRINT-DETAILS 5 TIMES

where GET-DETAILS is the first paragraph in the sequence and PRINTDETAILS is the last.

\section{Example}

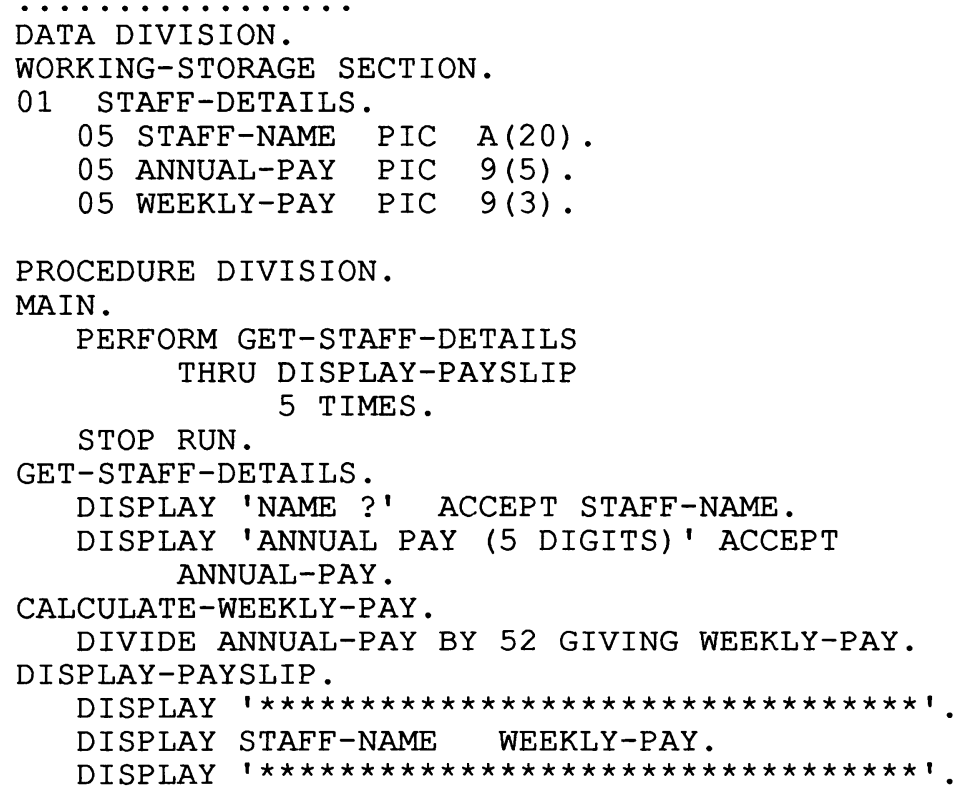

Exercises

1. What would happen if paragraph MAIN in the Example Program were changed to:

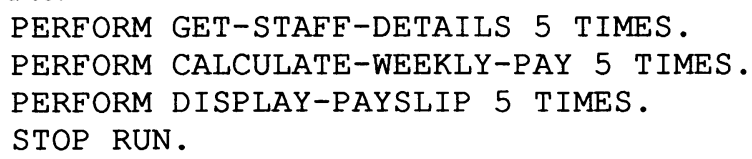

How does this differ from the example ? Which is correct for this particular program?

2. Change the example program so that the computer PERFORMs a paragraph called PRODUCE-PAYSLIP 5 times; this paragraph in turn instructs the computer to carry out GET-STAFF-DETAILS, CALCULATE-WEEKLY-PAY, and DISPLAY-PAYSLIP. 